\title{
DEPENDENCIA Y LIBERACIÓN EN LA FILOSOFÍA LATINOAMERICANA
}

En agosto de 1973 en Buenos Aires, y en septiembre del mismo año en Lima, me encontré, por última vez con Augusto Salazar Bondy. A la Argentina nos llevó nuestra participación en la discusión de un tema que nos era entrañable: el de la dependencia de la cultura latinoamericana y el de la posibilidad de una filosofía de liberación que cancelase esa dependencia, o fuese el futuro de ella. Una misma preocupación, pero un distinto enfoque respecto a sus problemas y soluciones. De ello hablamos en los ratos en que pudimos hacerlo a nivel personal continuando el diálogo expuesto ya en sendos libros.* Quedamos en repensar estos problemas y soluciones, lo cual hago en el trabajo que aquí presento. Lo que ya no puedo hacer es cumplir mi ofrecimiento de hacérselo llegar previamente para recibir su contestación y, acaso, publicar ambos trabajos juntos. Que sea este trabajo, manco, un homenaje fraternal a su recuerdo.

Entre los sociólogos, antropólogos sociales, psicólogos y economistas latinoamericanos, ha venido siendo centro de preocupación el problema de la dependencia. El problema de la dependencia característica de los pueblos latinoamericanos y, por supuesto, de los pueblos que, en otras zonas del mundo, Asia, Africa y Oceanía, han sido y aun son objeto de dominio. La filosofía no podía escapar a esta preocupación. No me refiero, por supuesto, a la filosofía que repite este o aquel profesor en su cátedra, siguiendo una determinada corriente nueva o anacrónica, sino a la filosofía de quienes habiendo asimilado la filosofía en estricto sentido, se encuentran con que esta asimilación ha sido realizada bajo el signo de la dependencia. Dependencia dentro de un sistema hecho, cerrado a un cambio que altere las verticales relaciones de dominación. Ha sido la conciencia de esta situación, la que ha originado la demanda para lo que se viene llamando filosofía de la liberación.

¿Cuál ha de ser esta filosofía? ¿Aquella por la cual han de trabajar nuestros filósofos si quieren ser algo más que profesores de filosofía? Augusto Salazar Bondy ha contestado: es claro "que la filosofía que hay que construir no puede ser una variante de ninguna de las concepciones del mundo que corresponden a centros de poder de hoy, ligadas como están a los intereses y metas de esas potencias. Al lado de las filosofías vinculadas con los grandes bloques actuales o del futuro inmediato es preciso, pues, forjar un pensamiento que, a la vez, arraigue en la realidad histórico-social de nuestras comunidades y traduzca sus necesidades y metas, sirva como medio para cancelar

- Augusto Salazar Bondy, ¿Existe una filosofia de nuestra América?, Siglo XXI, México, 1969. Leopoldo Zea, La filosofía americana como filosofia sin más, Siglo XXI, México, 1969. 
el subdesarrollo y la dominación que tipifican nuestra condición histórica".1 Hace ciento treinta y dos años, en $184^{2}$, otro latinoamericano, el argentino Juan Bautista Alberdi, hablaba ya de una filosofía semejante diciendo: nuestra filosofía, "ha de salir de nuestras necesidades. Pues, según estas necesidades, ¿̨cuáles son los problemas que la América está llamada a establecer y resolver en estos momentos? Son los de la libertad, de los derechos y goces sociales de que el hombre puede disfrutar en el más alto grado en el orden social y político". La filosofía de la liberación de que habla Salazar Bondy, por sus metas, habrá de ser esencialmente política; la filosofía de que hablaría Alberdi también, de acuerdo con las siguientes palabras: "De aquí es que la filosofía americana debe ser esencialmente política y social en su objeto, ardiente y profética en sus instintos, sintética y orgánica en su método, positiva y realista en sus procederes, republicana en su espíritu y destinos." 2

Filosofía política, social en ambos casos. Filosofía de liberación. Porque de liberación es también la filosofía que proponía, hace ciento treinta y dos años Juan Bautista Alberdi. El pensador argentino pertenece a la generación que, en aquellos años, se propuso liberar a los latinoamericanos de las cadenäs invisibles, pero no menos poderosas, que habían impuesto a sus hombres tres siglos de dominio colonial ibero en América. Una generación, entre los que se cuentan, además de Alberdi, Domingo Faustino Sarmiento, Victorino Lastarria, Francisco Bilbao, Juan Montalvo, José María Luis Mora; José de la Luz y Caballero, Andrés Bello y otros muchos más a lo largo de esta parte de nuestro continente. Una generación que consideraba insuficiente la emancipación política alcanzada, porque la misma no iba seguida de lo que llamaron "emancipación mental", cultural. Había también que independizarse de los hábitos y costumbres que un largo dominio había impuesto a los latinoamericanos. Esto es independizarse de un cierto modo de pensar y actuar que correspondía, con palabras nuevas, a la programación hecha por los centros de poder de aquella época. No pensar, ni actuar, en función con la programación impuesta por los dominantes centro de poder de ayer, y. de hoy, es lo común a la filosofía propuesta por la generación de Alberdi en el siglo pasado a la generación de Salazar Bondy en nuestros días.

Pero, ¿qué ha sucedido en ese largo lapso que separa a una generación de otra? ¿Por qué se sigue planteando la problemática de la liberación? ¿Qué sucedió con esa filosofía que se pensó para la emancipación mental latinoamericana que, al parecer, no funcionó? ¿Por qué sigue siendo ésta la problemática de nuestro pensamiento? Porque ésta no es, precisamente, la problemática propia de la filosofía que nos ha inspirado una y otra vez, o sea de la filosofía europea, occidental y universal, como se le llame. Al parecer, no

1 Augusto Salazar Bondy, op. cit., p. 127.

2 Juan Bautista Alberdi, Ideas para presidir a la confección del curso de filosofia contemporánea en el Colegio de Humanidades, Montevideo, $184^{\circ}$. 
funcionó la preocupación realista de la generación de Alberdi, pensándose no a partir de la propia realidad, sino a partir de nuevos centros de poder. Precisamente de los centros de poder que estaban desplazando al orden colonial del que trataban de sacudirse los latinoamericanos de aquellos días.

$\mathrm{Y}$ ahora, como ayer, se vuelve a proponer una filosofía que, para escapar a ese dominio mental y cultural, pretende partir de cero. Pero de cero respecto al pasado, el pasado colonial, el único pasado con el cual cuentan los latinoamericanos. La generación alberdiana se preocupaba, también de manera muy especial y radical, de borrar la herencia mental y cultural recibida bajo el dominio ibero, ya que la misma ocultaba cadenas más sutiles, aunque no menos efectivas que las cadenas de la dominación material. Pero, este partir de cero - pese a su supuesta radicalidad, expresado en la disyuntiva de un Sarmiento, "Civilización o barbarie", de un Bilbao, "Catolicismo o republicanismo", de un Mora, "Progreso o retroceso"-, no será tan radical, en cuanto se aceptarán modelos extraños de acuerdo a los cuales conformar el pensamiento, ordenar la mente. Se aceptan modelos filosóficos que se suponía podían ser útiles para formar una nueva mentalidad. Precisamente la mentalidad de hombres que hicieran por la América Latina lo que otros hombres, formados en la misma filosofía, habían hecho por naciones como Francia, Inglaterra y los Estados Unidos. El mismo Alberdi, en las lecciones a que hacemos referencia, seleccionaba ya los modelos de filosofía que podrían ser adaptados y útiles para los fines que consideraba propios del hombres de esta América. Un no a la metafísica, a lo abstracto. Y sí a la experimentación, al utilitarismo, a la filosofía de la acción. "La abstracción pura, la metafísica en sí - dice-, no echará raíces en América." Los Estados Unidos ya han mostrado que ésta no es necesaria para "conseguir un desenvolvimiento político y social". Ellos han hecho un orden social nuevo y "no lo han debido a la metafísica". Y resumiendo su pensamiento declara: "Si es posible decirlo, la América practica lo que piensa Europa." ${ }^{3}$ De aquí se pasará fácilmente a la declaración de Sarmiento: "Seamos la América como el mar es el océano. Seamos Estados Unidos." "4

Habrá que borrar la herencia ibérica, habrá que borrar a España, dirán los hispanoamericanos, para poder ser como los grandes modelos de la modernidad, para poder ser como los Estados Unidos. Se parte de cero respecto a sí mismo, pero se pretende, al mismo tiempo, partir de una concepción del mundo y cultura que nos es extraño, partir de un pasado que no hemos hecho. De esta manera se espera alcanzar un futuro semejante al logrado por los pueblos que han partido del pasado que se quería adoptar. Salvo que este pasado era el propio de estos pueblos; el pasado sobre el cual se

3 J. B. Alberdi, op. cit.

4 Domingo F. Sarmiento, Conflicto $y$ armonia de las razas en América, La Cultura Argentina, Buenos Aires, 1915. 
había alzado su presente y se estaba levantando su futuro. Por ello, será este pasado extraño a Latinoamérica, esta filosofía extraña a nuestra realidad, aunque haya sido entrañable a la realidad de los hombres que lo crearon, el que nos plantee el nuevo problema. El problema sobre la posibilidad de una nueva filosofía. De una filosofía que rompa nuevos encadenamientos. Ya que, al parecer, la propuesta de la generación latinoamericana de 1840 sólo sirvió para un simple cambio de dominación. Pues ha sido precisamente esa filosofía utilitaria, pragmática, lo que ha hecho posible los nuevos imperios, y ha dado origen a nuevas subordinaciones, y encadenamientos que ahora hay que romper. De allí la nueva demanda de una filosofía de la liberación. De una filosofía que acaso haga por los latinoamericanos lo que no hizo la filosofía de la liberación que se creyó antes haber encontrado. Filosofía de la liberación para sus creadores, pero de dominación para quienes pretendieron alcanzar sus frutos sin haber sembrado sus semillas.

II

Es interesante destacar la reacción que frente a la filosofía de liberación de la generación de Alberdi, tiene otro argentino - uno de los sostenedores de la filosofía de la liberación de nuestros días_, Enrique D. Dussel. Al hacer referencia a Sarmiento, cuando éste plantea la disyuntiva entre barbarie y civilización, lo cita cuando dice "se ven a un tiempo dos civilizaciones distintas en un mismo suelo: una paciente que, sin conocimiento de lo que tiene sobre su cabeza, está remedando los esfuerzos ingenuos y populares de la Edad Media; otra que, sin cuidarse de lo que tiene a sus pies, intenta realizar los últimos resultados de la civilización europea". "Estos intelectuales -comenta Dussel-, filósofos en potencia o sofistas en ejercicio, sólo supieron repetir (no pensar) el pensar preponderante europeo y definieron a la América Latina como ámbito periférico del nordatlántico. Es decir, aceptaron la dominación cultural y la hicieron esencia de nuestro pueblo latinoamericano. Civilización y barbarie: la civilización es la totalidad organizada y dominada por Europa (cuyas prolongaciones son los Estados Unidos y Rusia, como dice Heidegger), donde las colonias hispanas y neocolonias inglesas de América Latina quedan definidas dentro del Humanismo que se les enseña: la barbarie es la exterioridad, el no-ser, lo que se sitúa más allá del logos, el campo y la historia del indio, del mestizo, de la América Latina originaria y real." ' La barbarie es precisamente la América abajo del Río Bravo, la América que no ha sido cultivada, civilizada por la Europa occidental o su heredero, el pionero yanqui. Sarmiento, y con Sarmiento sus

5 Domingo F. Sarmiento, Facundo, La Cultura Argentina, Buenos Aires, 1915.

6 Enrique D. Dussel, Para una ética de la liberación latinoamericana, Siglo XXI, Buenos Aires, 1973, t. II, p. 194 . 
equivalentes en Latinoamérica, culminando con los positivistas latinoamericanos, aceptan la calificación que este mundo occidental da a los pueblos que están más allá de sus fronteras e intereses, justificando su expansión en los mismos. Estos intelectuales, desterrados de Europa, pero que tampoco son parte de la América de los Washington, los Jefferson, los Adams y los Monroe, aceptan el papel de intermediarios, de cónsules o procónsules de la civilización en el mundo de la barbarie, supuestamente para incorporarla a los ámbitos de la civilización. Al igual que nuestras clases medias más tarde, nuestras seudoburguesías aceptan ser socios menores, pero siempre socios, de los nuevos centros de poder. Está América como brazo ejecutor de Europa. Fiel ejecutora de una voluntad que siéndole ajena, tan ajena como los intereses que ella implica, la hace propia y la sirve.

En el pasado, que ha de ser borrado de la mente del latinoamericano, está la barbarie. El pasado ibero, el pasado indígena y la mestización de ambos, dirá Sarmiento, encarnan la barbarie. Dentro de él, el hombre que ha de crear el futuro será un extraño; hombre sin raícés, armado de una filosofía que no le pertenece pero que ha de permitirle domar la barbarie; pero doma al servicio de los hombres que han creado esa filosofía, al servicio de los centros de poder que en ella se expresan. Un ente tan extraño como será el hombre de levita y bombín entre los salvajes hombre de las llanuras. "El hombre de la ciudad —dice Domingo F. Sarmiento-- viste el traje europeo, vive de la vida civilizada tal y como la conocemos en todas partes: allí están las leyes... Saliendo del recinto de la ciudard todo cambia de as pecto: el hombre de campo lleva otro traje... y el que osara mostrarse con levita, por ejemplo, y montado en silla inglesa, atraería sobre sí las burlas y las agresiones brutales de los campesinos." 7

De estos extraños, hablará años más tarde José Martí: "Éramos una visión, con el pecho de atleta, las manos de petimetre y lá frente de niño. Eramos una máscara, con los calzones de Inglaterra, el chaleco parisiense, el chaquetón de Norte América y la montera de España." Para Martí "el problema de la independencia no era el cambio de formas, sino el cambio de espiritu". Porque esta América si habría de salvarse, tendría que hacerlo con todo lo que en realidad era, con su violento pasado hispano, con sus indios, con sus mestizos. América tendría que salvarse con lo que es y con lo que ha sido. De otra forma quien se salvase sería un extraño. "La incapacidad -agrega Martí - no está en el país naciente, que pide formas que se le acomoden y grandeza útil, sino en los que quieren regir pueblos originales, de composición singular y violenta con leyes heredadas de cuatro siglos de práctica libre en los Estados Unidos, de diecinueve siglos de monarquía en Francia... el buen gobernante en América no es el que sabe cómo se gobierna el alemán o el francés, sino el que sabe con qué elementos está hecho el

7 D. F. Sarmiento, Facundo. 
pais." "El gobierno ha de nacer del país. El espíritu del gobierno ha de ser del país. La forma del gobierno ha de avenirse a la constitución propia del país. El gobierno no es más que el equilibrio de los elementos naturales del país." s Propuesta que, aparentemente, coincide con la de Alberdi y su generación. Salvo que el modelo adoptado, el que debería ser simple instrumento de realización de lo propio, se va a transformar en la generación de Alberdi, en arquetipo, en guía absoluto, en Arche, monarca, principal, primero y, por ende, en el que guia, el que manda y comanda.

Precisamente contra esta intromisión de un principio ajeno a la realidad y metas latinoamericanas, se alza la nueva filosofía que se llama, a sí misma, filosofía de liberación. Pero, una vez más, se vuelve a plantear la necesidad de borrar el nefasto pasado. De borrarlo, no de asimilarlo, para partir, nuevamente, de cero. Porque es en el pasado su intromisión, lo que también origina la inautenticidad de nuestra filosofía y nuestra cultura. La intromisión que llama Salazar Bondy "cultura de dominación". En este sentido, sostiene también Dussel, toda la filosofía occidental está hecha para dominar. Instrumento de dominación al servicio de su creador y, por ende, de encadenamiento para quienes, no siendo sus creadores, la adoptan. Porque adoptando esta filosofía se adoptan, también, las cadenas que la misma impone sobre otros hombres a quienes se regatea su humanidad. Por ello habrá entonces que borrar, que cancelar, la relación con una tal filosofía y su cultura, con una filosofía y una cultura dominadora, para crear, por el contrario, una filosofía y una cultura libertadoras, las cuales sean expresión de la libertad del hombre, del hombre como libertad. Nuestros abuelos, en el siglo xIx, intentaron lo mismo; pero sólo para caer, libremente, en nuevas dominaciones. Ellos rechazaban un modelo de dominación, pero para librarse de él aceptaron otro. $\mathrm{Y}$ de este otro tratamos ahora de liberarnos; pero no para caer en un nuevo encadenamiento que parece no tener fin.

\section{III}

¿Qué es el pasado para la nueva expresión de la filosofía de la liberación? El pasado es el dominio extraño y la aceptación consciente, o inconsciente, de este dominio. ¿De qué depende la posibilidad de un cambio? Augusto Salazar Bondy contesta: "El problema de nuestra filosofía es la inautenticidad. La inautenticidad se enraiza en nuestra condición histórica de países subdesarrollados y dominados. La superación de la filosofía está, así, intimamente ligada a la superación del subdesarrollo y la dominación, de tal manera que si puede haber una filosofia auténtica, ella ha de ser fruto de

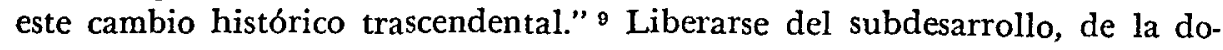

8 José Marti, Nuestra América, El Partido Liberal, México, 1891.

9 Augusto Salazar Bondy, op, cit., p. $15^{1}$. 
minación, tiene que ser, necesariamente, el paso que deben realizar, y con gran urgencia, nuestros pueblos. Pero el pensar, el filosofar, para actuar en este sentido, el filosofar para la liberación, la filosofía de la liberación, no puede depender de ese cambio. Por el contrario, ha de ser la conciencia de la situación de dominación la que origine la acción para la liberación. En este sentido, la filosofía que reflexione sobre su realidad - no la filosofía que repita lecciones y vea la propia realidad en función con modelos que le son extraños- será necesariamente filosofía auténtica. Una autenticidad que no puede depender de la superación del subdesarrollo, sino que ha de preceder a éste como conciencia. Sin embargo, poco después la postura que fuera un tanto pesimista del filósofo peruano, se reduce en cuanto acepta lo que llama la "reconstrucción del pensamiento filosófico". Esto es, la crítica a la filosofía de dominación, que sería, simultáneamente, crítica a los centros de poder que la han orignado. Sin embargo, esta misma crítica, este reflexionar sobre la dominación, dependerá en último término del cambio de estructuras, de un cambio que se antoja milagroso. No basta, dice Salazar Bondy, equiparse con un buen instrumental filosófico en la Sorbona, Oxford - Moscú. Lo que hay que hacer es "un trabajo crítico en la medida en que la realidad histórica lo permita, un trabajo de replanteo en la medida en que vamos emergiendo hacia una óptica nueva, y una reconstrucción de la filosofía, en la medida en que esa óptica nos da una manera de producir un pensamiento ya orientado en el sentido de la filosofía de la liberación". ${ }^{10}$ Una filosofía, como se ve, pese a su intención, dependiente. Dependiente de un cambio estructural, histórico, de la óptica de la cual ha de emerger la nueva filosofía. La inautenticidad, quiérase o no, sigue presente en cuanto es enfocada con una lógica formal, de enfrentamiento y no de absorción. No se niega la filosofía de la dependencia dentro de una lógica como la de Hegel y Marx, una lógica dialéctica, reconstruyendo la filosofía mediante una negación asimiladora. Por el contrario se intenta, una y otra vez, partir de una nada que no existe. Porque el pasado está allí, colonial o no, dependiente o no. Ése es el pasado que ha de ser negado, pero de forma tal que el mismo hecho de haber sido impide que siga siendo o vuelva a ser.

Algo semejante propone el filósofo argentino, Enrique D. Dussel, mostrando el carácter dominador de la filosofía occidental. Sugiere partir de la crítica de esta filosofía, descubriendo y mostrando sus resortes al servicio de la dominación. Hacerlos conscientes para destruirlos, sólo que aquí Dussel entiende la destrucción en un sentido hegeliano. Esto es, asimilar esta filosofía - tomando conciencia de su característica justo al servicio de la dominación de sus creadores- para hacer una filosofía nueva, una filosofía de liberación que nada tenga que ver con aquélla. El punto de partida de esta nue-

10 Augusto Salazar Bondy, "Filosofía de la dominación y filosofía de la liberación", Stromata, San Miguel, Provincia de Buenos Aires, oct.-dic., núm. 4, p. 397. 
va filosofía es el de una lucha abierta, mortal enfrentamiento, el de la anulación que permita al latinoamericano cerar algo nuevo, sin la contaminación dominante del pasado. Se debe, por ello, partir de la filosofía de la dominación para destruirla y crear la nueva. "En primer lugar como filósofos latinoamericanos del pasado debemos partir de la filosofía aprendida, de la europea, la única que en verdad se ejercía en nuestro mundo contemporáneo." 11 Pero, ¿qué pasa con el pasado filosófico latinoamericano, con este pensamiento? Este pasado es, precisamente, la expresión de la inautenticidad. En todo caso habrá que ir a él, pero sólo para mostrar su inautenticidad. Se dan dos vacíos: vacio por el lado de la filosofía europea, que parece sernos ajena, y por el pensamiento latinoamericano que se considera su apéndice, su repetición, expresión de una filosofía extraña a la propia realidad. Respecto a esta filosofía latinoamericana dice Salazar Bondy: "Sostengo que la filosofía, como producto de expresión de una cultura, cuando se trata de una filosofía que se hace dentro de un país que está en situación de dominación, es una filosofía que tiene los mismos caracteres, o sea, es una filosofía de la dominación." "Digo - insiste — que nuestra filosofía, la filosofía de nuestra América, de cada uno de los países o del conjunto de los países latinoamericanos, es una filosofía de la dominación, y por lo tanto defectiva." 12 Enrique Dussel en forma más tajante, sostiene que la tarea de la filosofía latinoamericana, la auténtica, la que se está iniciando con la filosofía de la liberación, "no es comentar lo que la filosofía latinoamericana anterior hizo, aunque no debe desconocérsela, ya que está viciada en lo esencial de la alienación propia de toda cultura colonial", ya que éste "era un pensar que estudiaba el pensar europeo y que de esta manera desembocaba en la realidad europea que aquel pensar pensaba. El pensar latinoamericano era sí inauténtico por dos razones: porque pretendía pensar, y como el pensar es pensar la realidad, el pensar latinoamericano era a lo más estudio y casi siempre mera repetición superficial; pero, y es lo más grave, al pensar el pensar europeo se ignoraba la realidad latinoamericana y se hacía pasar aquí por realidad la realidad metropolitana, imperial, moderna, dominadora". Así el filósofo latinoamericano, repetidor, inauténtico, "éticamente se tornaba culpable, aunque no tuviese conciencia refleja de dicha culpabilidad, porque era responsable de la alienación cultural del latinoamericano". ${ }^{13}$ Una vez más, como se observa, vacío de pasado, lo mismo del europeo por ser instrumento de dominación, como del latinoamericano por ser expresión de esa dominación. ¿Qué queda por hacer entonces? Empezar todo de nuevo. El mismo proyecto de la generación pensadora del siglo xrx, a la que ahora se enjuicia por inauténtica. Esa generación, pese a sus pretensiones de partir

11 Enrique D. Dussel, op. cit., t. I, p. 11.

12 Augusto Salazar Bondy, op. cit., p. 344 .

13 Enrique D. Dussel, op. cit., p. 11. 
de cero, adoptó un modelo. Un modelo cultural, filosófico que ahora se ve como el caballo de Troya del neocolonialismo. ¿Parte ahora el nuevo intento de filosofar de ese cero que propone o, por el contrario, lleva ya en su pretensión un nuevo caballo de Troya que justifique nueva dominación?

La filosofía de la liberación de que habla Dussel se presenta como pura y simple utopía. Será a partir de la crítica de la filosofía europea, la única que hemos aprendido, de donde surja una nueva filosofía. De esta filosofía dice: “... por encontrarnos más allá de la totalidad europea, moderna, dominadora (la nueva filosofía) es una filosofía del futuro, es mundial, posmoderna y de liberación. Es una cuarta Edad de la filosofía y la primera Edad antropo-lógica: hemos dejado atrás la fisio-logía griega, la teo-logía medieval, la logo-logía moderna, pero las asumimos en una realidad que las explica todas ellas". Es "la filosofía de los pueblos pobres, la filosofía de la liberación humano mundial". En otras palabras, la filosofía de que habla Dussel, será la asunción, por la vía crítica, de toda la filosofía europeo-occidental, la asunción de todo lo que el propio Dussel ha aprendido de ella, dentro de una postura supuestamente nueva, pero con rechazo de toda filosofía que antes de él se haya producido en Latinoamérica, por considerarla inauténtica, como expresión de la dominación que debe ser anulada. ¿Cómo ha de ser esta nueva filosofía? "La filosofía latinoamericana es, entonces -sigue Dussel-, un nuevo momento de la historia de la filosofía humana, un momento analógico que nace después de la modernidad europea, rusa y norteamericana, pero antecediendo a la filosofía africana y asiática posmoderna que constituirán con nosotros el próximo futuro mundial." 14 Una filosofia, de cualquier forma, ansiosamente dependiente de la filosofía occidental, de la que se aspira a ser epígono. ¿No es éste el viejo sueño de nuestros mayores? ¿el ser como el gran modelo, prolongarlo y superarlo?

Augusto Salazar Bondy es más sencillo, no aspira a una filosofía como epígono de filosofía alguna. Quiere una filosofía que exprese la liberación de Latinoamérica - y de los pueblos que se encuentran en su misma situación- de una dependencia que no debe ya existir. Esta filosofía, más que una filosofía de la liberación, deciamos, sería una filosofía posterior a la liberación, filosofía de hombres libres y no ya de hombres que luchan por su libertad. Aquí también el futuro, como utopía, con repudio del pasado y del presente. En cuanto al modelo, el mismo modelo occidental, el de una sociedad desarrollada. Ya que de este desarrollo depende la realización de esa utopia. En este caso es filosofía auténtica aquella que, con su crítica, ayuda a la posibilidad del desarrollo. El desarrollo que han alcanzado otros pueblos y deben también alcanzar los nuestros. Pero un desarrollo que dependerá del modelo dominado, de lo que éste vaya permitiendo con sus pro-

\footnotetext{
14 Enrique D. Dussel, "Filosofía latinoamericana y método analítico", en Latinoamérica, Anuario de Estudios Latinoamericanos, 6, unAM, México, 1973, pp. 19o-131.
} 
pias contradicciones. "Seamos los Estados Unidos de la América del Sur", decía Sarmiento. Alcancemos el desarrollo de los pueblos dominadores, nos dice de alguna forma Salazar Bondy, y seremos, como los hombres que han hecho estos pueblos, hombres libres, libre será también nuestra cultura y nuestra filosofía. El mismo viejo proyecto, pero una vez más, intentando anular la propia realidad a través de una lógica que no acepta contradicciones, que no puede asimilar.

\section{IV}

Ser como los Fstados Unidos, ser como el mundo occidental, la URSS o China occidentalizadas, sigue siendo la meta y el modelo a realizar. En este sentido la filosofía de la liberación sostenida por Salazar Bondy coincide con las preocupaciones de un Luis Villoro, quien sostiene abiertamente una determinada filosofía, pero sin pretender originalidad alguna aunque intenta alcanzar la misma meta, el mismo desarrollo, el ser semejante a los grandes modelos del progreso y civilización contemporáneas. Luis Villoro, en sus "Perspectivas de la filosofía en México para 1980", sostiene la misma tesis de Salazar Bondy respecto al pasado y al futuro de la América Latina, respecto a su cultura, a su filosofía, pero sin llamarla filosofía de liberación. Villoro, inclusive, apoya en el trabajo de Salazar Bondy su crítica a la inautenticidad de la filosofía que en el pasado se ha hecho en Latinoamérica. La filosofía que Villoro propone no es llamada, decíamos, de liberación, la llama filosofía profesional. Una filosofía que vendrá a ser, también, expresión del paso de una etapa de subdesarrollo. Esta filosofía será también expresión del desarrollo que los pueblos, como los latinoamericanos, vayan alcanzando. El mismo gran modelo, en sus diversas expresiones, sigue mostrando la meta por alcanzar y la posibilidad de esa supuesta filosofía. "La producción filosófica de nivel profesional - dice Villoro- requiere de ciertas condiciones mínimas y no puede aparecer hasta que éstas existan." Porque "si bien es cierto -acepta Villoro - que en otras épocas pudo darse el filósofo creador aislado o en pequeñas comunidades, actualmente la producción filosófica requiere la permanencia de un clima de investigación, de crítica y discusión que sólo se alcanza en los medios universitarios, supone la existencia de una comunidad de especialistas capaces de comunicarse constantemente entre sí y con los medios extranjeros donde se realicen trabajos semejantes. Fuera de esas comunidades la filosofía será inevitablemente obra de aficionados o de divulgadores de cultura". La filosofía profesional de que habla Villoro, como la de liberación de que habla Salazar Bondy, dependerá como éste decía de la cancelación del subdesarrollo. "Y la realización de estos requisitos - los propios de la filosofía profesional, dice Villoro- presupone que la sociedad haya entrado en una cierta etapa de desarrollo." 
Villoro, al igual que quienes proponen la filosofía de liberación, lanza por la borda todo el pasado filosófico latinoamericano por inauténtico, por falta de profesionalismo: "Antropologismo, psicologismo, historicismo tocan a su fin —dice-, al igual que el tipo de sociedad a la que respondian." "El historicismo y el existencialismo, corrientes ligadas en nuestro medio con el intento de estudiar nuestra forma de ser nacional habrán sido abandonados." Existe, desde luego, una diversa interpretación del pasado filosófico latinoamericano entre Villoro y Salazar Bondy, aunque ambos lo consideran in: auténtico. Salazar Bondy ve en ese pasado filosófico e inauténtico el puro afán por imitar, repetir, filosofías extrañas. Villoro no; éste ve en ese pasado filosófico, también inauténtico, un afán de originalidad ajeno a toda verdadera filosofía, a su profesionalismo. El desarrollo, dirá Villoro, cancelará el afán de originalidad. Un afán que nos ha apartado y desligado del progreso universal. La búsqueda de lo original, de lo que se consideró como propio, lo nacional, es sólo expresión de sociedades cerradas, limitadas, subdesarrolladas. Ahora hay que pasar a una sociedad abierta, universal, desarrollada. El pasado filosófico de que ha hablado Villoro, "correspondía a una sociedad relativamente cerrada en sí misma, preocupada por su unidad. En la medida en que esta sociedad entra en desarrollo, cobran importancia grupos sociales con intereses supranacionales y se impone una franca apertura hacia el exterior". Apertura que llevará "implícito el abandono progresivo del nacionalismo cultural y el acceso a un nuevo universalismo".

Ahora bien, ¿el desarrollo implicará simplemente nuestra incorporación, en otro plano que no sea el de dependencia, al sistema del que ahora nos sabemos dependiente? ¿Nos disolveremos en el modelo pura y simplemente? Por ello, la futura filosofía, lejos de seguir urgando en las peculiaridades propias de los pueblos, deberá abandonarlas por anacrónicas y, por ende, por inauténticas. El desarrollo anhelado por Salazar Bondy y Villoro dará origen a un nuevo filosofar y a una nueva función del filósofo en la sociedad. "El desarrollo económico del país - dice Villoro-_ también se traduce en un cambio en la función del filósofo. Una sociedad en vías de desarrollo tiene de la filosofía una necesidad distinta a una sociedad subdesarrollada." "El filósofo puede ser un creador más o menos original, pero no logra ser propiamente un especialista en nada, salvo justamente en generalidades. Con el desarrollo se abre al filósofo otra función que exige de él una especialización mayor." "El filósofo debe cumplir una función auxiliar en el desarrollo armónico de las ciencias." ${ }^{15}$ La filosofía como nueva servidumbre, como simple instrumento, en una sociedad desarrollada, no importa el signo de la misma, capitalista o socialista, o bien, como diría André Gunder Frank, desarrollada

15 Luis Villoro, "Perspectivas de la filosofía en México para 1980", en El perfil de México en 1980, Siglo XXI, México, 1972. 
dentro de los límites del subdesarrollo, esto es, dentro de viejas o nuevas formas de dependencia.

Tal conclusión negaría, si no la propuesta de Villoro, sí la de la filosofía de liberación propuesta por Salazar Bondy. La futura filosofía no podrá ser una variante de las concepciones del mundo que corresponden y responden a los centros de poder de nuestros días. Sería una filosofía más justificadora de los intereses de este o aquel centro de poder, por universal que sea tal centro, y una expresión de su dominio. A eso se reduciría la universalidad de tal filosofía. ¿En qué descansa, entonces, la coincidencia que encontramos entre la filosofía de liberación de Salazar Bondy y la filosofía profesional de Villoro? En la meta por alcanzar, en la simple cancelación del subdesarrollo. La diferencia habrá que encontrarla en él para que dé tal desarrollo. ¿Simplemente se trata de alcanzar las metas que han alcanzado otros pueblos? O bien, ¿se trata de que el hombre de esta América, como el de cualquier otra parte del mundo, se libere de toda forma de dependencia? Pero al hablar del hombre, nos referimos al hombre concreto, al hombre que es cada uno de nosotros sin discriminación alguna. Sarmiento y sus pares en Latinoamérica se propusieron la primera meta, esto es, trataron de igualar a sus pueblos con los modelos que ofrecían las naciones que habían alcanzado el progreso, el desarrollo. La nueva dependencia, la que ahora se combate, la facilitó la dependencia propia del discípulo con el maestro. ¿Regresamos ahora a la misma pretensión? ¿Insistimos en ser como los Estados Unidos y la Europa occidental? O bien, en ser como la urss o China que han alcanzado esas metas sin caer en la dependencia del modelo? $O$ bien, ¿pretendemos algo más simple, pero más difícil de alcanzar, la liberación del hombre, su desenajenación, en cualquier situación en que se encuentre, tanto en el subdesarrollo como en el máximo desarrollo? Se nos podrá contestar, desde luego, que esto último dependerá del logro de lo primero. Se nos dirá que será de la cancelación de la subordinación social, política y económica de lo que dependa la liberación de los hombres concretos de que hablamos? ¿Por qué, entonces, la crisis moral que, desde hace algunas décadas, se hace sentir en los países que han alcanzado mayor desarrollo como los Estados Unidos y las naciones de la Europa occidental? ¿Por qué, también aquí, la demanda de libertad y la denuncia de enajenaciones que la impiden? ¿Por qué, precisamente, el enfrentamiento contra el sistema que es expresión del desarrollo alcanzado? Por lo que se refiere a nuestros pueblos, ha sido en nombre de la posibilidad del progreso, ayer, del desarrollo ahora, como se han justificado banderas como "orden para la libertad" y las llamadas democracias dirigidas.

Frantz Fanon, pensador afrolatinoamericano, se hace también la pregunta: 
¿Queremos ser como Europa, como los Estados Unidos? Dejemos entonces que sean los Estados Unidos y Europa los que se encarguen de esta hechura. ¿Queremos que nuestros pueblos se asemejen a los grandes modelos de nuestros días, además de los Estados Unidos y Europa, la URss y China? Pidámosles entonces a ellos se encarguen de esta tarea. Después de todo, ha sido y seguirá siendo la preocupación de esas potencias el formar a otros pueblos a su imagen y relativa semejanza. "Pero si queremos que la humanidad avance con audacia, si queremos elevarla a un nivel distinto del que le ha impuesto Europa, entonces hay que inventar, hay que descubrir. Si queremos responder a la esperanza de nuestros pueblos, no hay que fijarse sólo en Europa." Pero no se trata sólo de la propia liberación y felicidad, sino de la liberación y felicidad del hombre sin más. En el proyecto de liberación y felicidad del latinoamericano debe expresarse también el proyecto de una liberación total del hombre. Pero del hombre concreto, insistimos. La propia liberación deberá incluir la liberación de los hombres. Una extensión de la liberación, pero en un plano que no implique dependencia alguna, no se trata de que unos hombres liberen a los otros, de un problema de solidaridad, sino en que los unos a los otros se liberen y alcancen en conjunto la felicidad. Por ello Fanon piensa a la liberación americana, africana, asiática y del Tercer Mundo en general, en función con la totalidad de la humanidad, incluyendo a la propia Europa, al mundo occidental. “... Si queremos - dice- responder a la esperanza de los europeos, no hay que reflejar una imagen, aun ideal, de su sociedad y de su pensamiento, por los que sienten de cuando en cuando una inmensa náusea. Por Europa, por nosotros mismos y por la humanidad, compañeros, hay que cambiar de piel, desarrollar un pensamiento nuevo, tratar de crear un hombre nuevo."

Si hemos de crear una filosofía, como expresión de una cultura y una sociedad libres, una filosofía que sea expresión de nuestra realidad y sirva a la satisfacción de sus intereses y la solución de sus problemas, tendremos que hacer lo mismo que hacen los grandes modelos, los que han sido nuestros arquetipos, esto es, ponernos pura y simplemente a la tarea de su realización pero sin pretender semejarnos a ningún modelo, pero tampoco pretendiendo ser epígonos de sus expresiones. Las semejanzas surgirán naturalmente; pero como expresión de la humanidad de sus creadores. Obra de hombres y para hombres, que en este sentido cultura y filosofía son una de sus tantas expresiones. Desde este punto de vista participaremos en una tarea que no tiene que ser necesariamente imitativa o repetitiva. Por el contrario, siendo auténticos, en cuanto expresemos nuestro propio modo de ser sin pretender ser otro, colaboraremos en la nunca terminada búsqueda de la libertad y felicidad humanas. Los Estados Unidos, Europa, la urss, China y el resto de los pueblos del mundo, podrán contar $\mathrm{y}$, acaso, agradecer nuestro aporte, por limitado que éste pueda parecer. El aporte de un grupo de hombres a las. 
experiencias con que se va nutriendo la comunidad de todos los hombres. Responderemos así no sólo a la esperanza de nuestros pueblos, sino también a la de otros muchos pueblos que encóntrarán en nuestras experiencias lecciones que se acumulen a las propias para el logro de un cada vez más amplio porvenir. En este sentido la cancelación del subdesarrollo de pueblos como los nuestros, será la expresión de esa búsqueda y sus logros.

"Con el pretexto de alcanzar a Europa no hay que forzar al hombre, que arrancarlo de sí mismo —dice Fanon-, de su intimidad, no hay que quebrarlo, no hay que atarlo." Pues esto es lo que se ha hecho cuando se ha pretendido hacerle renunciar a lo que ha sido, por algo extraño a sí mismo. "No, no queremos alcanzar a nadie - sigue Fanon. Pero queremos marchar constantemente, de noche y de día, en compañía del hombre, de todos los hombres." Fanon incluye en éste "todos los hombres" a los mismos dominadores, que tendrán que dejar de serlo para estar verdaderamente acompañados. "Se trata, para el Tercer Mundo-dice_, de reiniciar una historia del hombre que tome en cuenta al mismo tiempo las tesis, algunas veces prodigiosas, sostenidas por Europa, pero también los crímenes de Europa, el más odioso de los cuales habrá sido... el descuartizamiento patológico de sus funciones... odios raciales, esclavitud, la explotación y, sobre todo, el genocidio no sangriento que representa la exclusión de mil quinientos millones de hombres." "No rindamos... un tributo a Europa creando estados, instituciones y sociedades inspirados en ella. La humanidad espera algo más de nosotros que esa imitación caricaturesca y en general obscena."

No se trata de echar nada por la borda, no se trata de partir de la nada, de cero, sino de todo lo que hemos sido. Habrá que partir de una clara conciencia de la dominación y de la forma como esa dominación ha sido justificada y también aceptada por nosotros. Habrá que partir de todo esto, ser consciente, para que todo eso deje de existr. Ese todo es nuestro pasado. Un pasado que no va a ser borrado simulando su olvido. El pasado está allí, tenemos que contar con él para que no siga siendo. El pasado es el material con el que hay que construir un hombre nuevo, un mundo nuevo, simple inversión de valores.

Frantz Fanon, en Piel negra, máscaras blancas, plantea, con hondura el problema de la imposibilidad de renunciar al pasado de otra forma que no sea su aceptación, su asimilación en función de un futuro que ha de ser distinto. Fanon habla de un pasado que es irrenunciable, el color de la piel, el ser negro. Un pasado que no puede ser olvidado como se pretende hacer con la cultura y la historia en que el colonizado se ha formado. El negro no puede dejar de ser negro aunque se pinte la cara o se ponga máscara de blanco. No puede dejar de ser negro, pero sí puede ser hombre, esto es, exigir el reconocimiento de su humanidad. Una humanidad que tiene como esencial la diversidad de sus múltiples individuos. Lo negro es expresión de 
esta individualidad. $\mathrm{Y}$ se reconoce a lo humano en su individualidad, en la diversidad, tanto física como cultural. Por ello el negro no tiene por qué arrancarse piel para ser hombre, tampoco arrancarse el pasado, la historia, para alcanzar lo que otros hombres han alcanzado. No se tiene que renunciar a sí mismo para cancelar el subdesarrollo. Para triunfar sobre el subdesarrollo, sobre la dominación, no será necesario ponerse una máscara extraña. Porque, con esa máscara, se estará aceptando una nueva forma de dominación, de dependencia. No es menester usar levita y bombín para ser civilizado, anulando la supuesta barbarie de las llanuras americanas. No es necesario imitar constituciones e instituciones propias de otras sociedades para ser liberales y democráticos: no ha bastado adoptar el positivismo para hacer de los latinoamericanos los sajones de Sudamérica. No bastará tampoco el supuesto profesionalismo filosófico para transformarnos en fabricantes de atómicas y naves de retropulsión. Nada de esto será suficiente si se quiere ser algo más que un hombre, ser otro hombre. Porque entonces dejaremos de ser hombres, tratando de ser otro distinto del que somos. Y tratando de ser otro que nosotros mismos dejaremos también de ser libres, ya que dependeremos de ese otro que no somos nosotros. No seremos libres por haber cancelado el subdesarrollo; más bien habremos cancelado el subdesarrollo por sabernos hombres libres.

Es esta libertad la que debe normar nuestras relaciones con el pasado, con lo que hemos sido y ya no puede ser cambiado, pero cuya conciencia puede servir para no seguir siéndolo. Por ello habrá que hacer consciente el pásado para que ya no sea, para que sea simple pasado. Una manera de ligarse al pasado, sin trascenderlo, lo ha sido el inútil afán de querer ignorarlo, de fingir que no existe, pretendiendo partir de nada. Por ello Fanon se enfrenta a esta forma de enajenación, diciendo, "no soy esclavo de la Esclavitud que deshumanizó a mis padres". No queriendo parecer lo que fui ¿dejo por ello de serlo? Agrega Fanon, tal hombre, "no queriendo parecer el pariente pobre ni hijo adoptivo ni retoño bastardo, ¿intentará descubrir febrilmente una civilización negra?" "La desdicha del hombre de color es haber sido esclavizado. La desdicha y la inhumanidad del blanco es haber matado al hombre en alguna parte." "Pero yo, hombre de color, en la medida en que me es posible existir absolutamente, no tengo derecho a acantonarme en un mundo de reparaciones retroactivas." 16 Porque el dominado, en la medida en que sólo ve agravios que ha de vengar en el futuro, agravios que ha de negar por la destrucción y no por la asunción, que ha de devorar y digerir, seguirá dependiendo de tal pasado. "El negro que quiere blanquear su raza es tan desgraciado como el que predica el odio al blanco." "¿Por qué no intentar, sencillamente, la prueba de tocar al otro, sentir al otro, revelarme

16 Frantz Fanon, Los condenados de la tierra, Fondo de Cultura Económica, México, 1963, pp. 288-292. 
al otro?" dice Fanon. "Que se me permita descubrir y querer al hombre, donde esté." ${ }^{17}$ Tal es una auténtica filosofía de la liberación, la que hace del pasado del hombre el instrumento de la superación de su presente en relación con un futuro que ha de serle propio y no ajeno. Una filosofía de liberación que no deje al hombre ni en el vacío de pasado ni en el vacío de futuro.

José Martí -al que la Revolución cubana ha asimilado como parte del pensamiento que culminó en el nuevo acto de liberación que representa esa revolución - ha dicho hablando de la generación que ya se perfilaba en su tiempo, y de la cual él iba a ser maestro: "Las levitas son todavía de Francia, pero el pensamiento empieza a ser de América. Los jóvenes de América se ponen la camisa al codo, hunden las manos en la masa y la levantan con la levadura de su sudor." Esta generación no quiere ya seguir imitando, quiere ser ella misma, quiere expresar su realidad, su historia, ser devoradora del pasado, que sólo de esta forma puede ser negado. Un pasado como alimento del que ha de brotar una vida. El pasado preñado de su propio futuro. Un pasado de luchas cruentas, entre el cirial y el libro, entre los intereses de casta y los intereses del pueblo que hace la riqueza con su trabajo, entre los que todo quieren y los que nada tienen. Sobre ese pasado contradictorio, beligerante, ha de alzarse el futuro haciendo de él la materia de lo que puede ser. Un ser distinto, un ser que no tiene por qué asemejarse a otro; individualidad que, para serlo, deberá hacer algo más que imitar, esto es, crear, inventar.

Los jóvenes, sigue diciendo Martí, "Entienden que se imita demasiado, y que la salvación está en crear. Crear es la palabra de pase de esta generación". "Se entiende que las formas de gobierno de un país han de acomodarse a sus elementos naturales; que las ideas absolutas, para no caer por un yerro de forma, han de ponerse en formas relativas; que la libertad, para ser viable, tiene que ser sincera y plena; y que si la república no abre los brazos a todos y adelanta con todos, muere la república." 18 El problema de la independencia, el problema de la libertad, diría Martí, no es un cambio de formas, sino un cambio de espíritu. Esto es, de actitud ante la realidad que ha de ser salvada, ante el mundo de que es parte esta realidad, una realidad que ha de ser ampliada, pero no como un apéndice de la misma. Una realidad que ha de ser al mismo tiempo amasijo para su creación. Medio y fin. Sólo así se será y se dejará de ser para ser algo distinto: pero no tan distinto que se deje de ser uno mismo enajenándose en otro. Sólo así se irá

17 Frantz Fanon, ;Escucha Blanco!, Editorial Nova Tierra, Barcelona, 1966, pp. 283-285 18 José Martí, op. cit. 
realizando una libertad que no depende de una determinada semejanza, con éste o aquel modelo. Una libertad que no descansaría ni en vacío ni de pasado, por lo que se quiere dejar de ser; ni en vacío de futuro por lo que se quiere llegar a ser.

La filosofía de la liberación ha de ser filosofía que salve al hombre, a cualquier hombre, de la enajenación impuesta o autoimpuesta. Que lo salve como totalidad, sin amputación ni del pasado ni del futuro. Salvación que se da, insistimos, no por la anulación del pasado, sino por la asunción del mismo. Por lo que llama Hegel Aufhebung. Esto es, por un hacerse y rehacerse de acuerdo con un pasado que es propio y en vistas a un futuro que debe ser igualmente propio. En ese pasado está ya lo que se quiere para el futuro pero que no ha sido consciente. La conciencia de este pasado permitirá, entonces, descubrir lo que el hombre ha venido anhelando para un futuro que ha de realizar si sabe con plenitud en qué consiste. Carlos Marx nos decía: "Nuestra divisa será, pues, la reforma de la conciencia... Se verá entonces que, desde hace mucho tiempo, el mundo posee el sueño de una cosa de la cual le falta la conciencia para poseerla de verdad. Se verá que no se trata de establecer una gran separación entre el pasado y el porvenir, sino de realizar las ideas del pasado. Se verá entonces que la humanidad no comienza una nueva tarea, sino que realiza su antiguo trabajo con conocimiento de causa." 19 Toma de conciencia plena, con unidad de lo que se ha sido, lo que se es y lo que se quiere llegar a ser. Unidad de lo humano en continua realización. Realización consciente a través de la cual se va haciendo expresa la anhelada libertad.

LEOPOLDO ZEA

Facultad de Filosofía y Letras

Universidad Nagional Autónoma de México

19 Carlos Marx, "Carta a Arnold Ruge Kreuznach", septiembre de 1843, publicada en los Anales Franco-Alemanes, París, 1844. En español en Ediciones Martínez Roca, Barcelona, 1970 , pp. $65-69$. 